\title{
Synthesis, Characterization and Photocatalytic Performance of Poly-3- Thenoic Acid/Cu-TiO 2 Nanohybrid for Efficient Visible Light Assisted Degradation of Bismarck Brown R
}

\author{
Imandi Manga Raju, Tirukkovalluri Siva Rao* and Miditana Sankara Rao \\ Department of Inorganic \& Analytical Chemistry, School of Chemistry, Visakhapatnam 530003, \\ Andhra Pradesh, India
}

('Corresponding author's e-mail: sivaraoau@gmail.com)

Received: 19 August 2020, Revised: 7 March 2021, Accepted: 19 April 2021

\begin{abstract}
The present work reported on the synthesis and characterization of Poly-3-Thenoic acid/Cu-TiO 2 nanohybrid $(\mathrm{PCuT})$ for the photocatalytic degradation of organic azo dye pollutant from wastewater. The as-synthesized nanohybrid by an in-situ modified sol-gel method including chemical oxidative polymerization was characterized by X-ray diffraction (XRD), Fourier transform infrared (FT-IR) spectroscopy, UV-visible diffuse reflectance spectroscopy (UV-vis.DRS), scanning electron microscopy with energy-dispersive X-ray spectroscopy (SEM-EDX), transmission electron microscopy (TEM) and Brunauer-Emmet-Teller (BET) surface area analysis. The characterization results revealed the formation of small aggregates of polymer contained high crystalline anatase $\mathrm{TiO}_{2}$ nanoparticles (XRD) with narrowed bandgap energy (UV-vis.DRS), decreased particle size (TEM) with smooth surface morphology (SEM) and large surface area (BET). All the constituent elements of the polymer and $\mathrm{Cu}-\mathrm{TiO}_{2}$ were found in the PCuT nanohybrid material (EDX) and their chemical interaction studied by FT-IR confirmed the stability of the nanohybrid. The photocatalytic activity of the nanohybrid was tested by the degradation of Bismarck Brown R dye under visible light irradiation. To enhance the photocatalytic efficiency, effects of various catalyst/dye reaction parameters such as polymer content, solution $\mathrm{pH}$, catalyst dosage, and initial dye concentration were studied and optimized.
\end{abstract}

Keywords: Nanohybrid, Bismarck Brown R, Azo dye, Photocatalytic degradation, Modified sol-gel method

\section{Introduction}

$\mathrm{TiO}_{2}$ semiconductor-based nanocatalysts are being used for environmental remediation applications from past few decades due to its ecofriendly nature. Even though it has been widely using as a supreme photocatalyst for organic pollutants removal from wastewater, it has its own drawbacks of wide bandgap energy, $3.2 \mathrm{eV}$ (UV light active only), and rapid electron/hole recombination rate. To overcome these demerits, researchers around the world are finding the best possible methods to modify the band structure of $\mathrm{TiO}_{2}$ to make it visible light active such as doping/codoping with metal and/or nonmetal ions [1-7], noble metal deposition [8], making composite semiconductors [9-11] and surface polymer sensitization [12].

In addition, to overcome these demerits researchers in recent times are also focusing on the enhancement of the photocatalytic performance of the $\mathrm{TiO}_{2}$ to the maximum extent by combining the above-said methods i.e combination of metal doping and composite semiconductor or polymer and obtained promising results $[13,14]$. Hence, after careful recent literature survey we found that $\mathrm{Cu}$ doped $\mathrm{TiO}_{2}(\mathrm{CuT})$ reported by Nazil Turkten et al. showed improved photocatalytic activity due to its almost similar ionic radius with $\mathrm{Ti}^{4+}$ for effective doping, high electronic conductivity and cost effective [15]. In our recent finding's polymer modified-Cu doped $\mathrm{TiO}_{2}$ has shown enhanced photocatalytic performance under visible light irradiation compared to CuT alone [16,17].

Among the various conjugated polymers modified $\mathrm{TiO}_{2}$ photocatalysts, polythiophene derivatives exhibited better performance [18,19]. Among which Poly-3-Thenoic acid shows higher light absorbance capacity within the wavelength region from 200 to $800 \mathrm{~nm}$ and can effectively restricts the $\mathrm{TiO}_{2}$ particle growth during the synthesis process due to its electrostatic encapsulation. Compared to other polymorphs 
of $\mathrm{TiO}_{2}$, anatase phase stands as a prominent and promising phase for effective photocatalytic degradation of organic pollutants. Hence, in this study, we aimed to synthesize a Poly-3-Thenoic acid supported copper doped anatase $\mathrm{TiO}_{2}$ nanohybrid (PCuT) by an in-situ modified sol-gel method including chemical oxidative polymerization and study its structural, morphological and optical properties to understand its ability towards photocatalytic applications.

To investigate the photocatalytic performance of PCuT, Bismarck Brown R (BBR), a diazo dye pollutant was selected as a model organic pollutant for degradation experiments. "Disazo dyes, having 2 azo groups, like BBR, is highly toxic and carcinogenic. The other effects of dyes in water include reduction of oxygen levels; retards penetration of sunlight into water; which retards the growth of aquatic biota because of reduced photosynthetic action" [20]. In particular, Bismark brown $\mathrm{R}$ dye is used as biological stains, in coloring paper, pulp, wool, lather and hair etc. [21,22]. "Both, short time and prolonged contacts of the dye with the eye and skin causes severe irritation with redness at the site of contact. On ingestion, it produces gastrointestinal irritation with nausea, vomiting, diarrhea, soreness and redness of mouth and throat. On inhalation it produces irritation to the throat with a feeling of tightness in chest and may cause coughing and wheezing. It is also carcinogenic to human being and aquatic organism" $[23,24]$.

To attain efficient photocatalytic performance, degradation experiments were performed under simulated visible light irradiation by studying the effect of various reaction parameters such as polymer content, solution $\mathrm{pH}$, catalyst dosage, and initial dye concentration and optimized conditions were established.

\section{Materials and methods}

\section{Chemical reagents}

All the chemicals used in this research are of reagent grade and their solutions were prepared with Milli Q water. N-butyl tetra ortho titanate $\left(\mathrm{Ti}(\mathrm{OBu})_{4}\right)$, Copper chloride $\left(\mathrm{CuCl}_{2}\right)$, 3-Thiophene carboxylic acid monomer (99\%), Ammonium persulfate $\left(\left(\mathrm{NH}_{4}\right)_{2} \mathrm{~S}_{2} \mathrm{O}_{8}\right)$ and 2-propanol procured from E-Merck (Germany) were used to synthesize Poly-3-Thenoic acid/Cu- $\mathrm{TiO}_{2}$ nanohybrid. Commercially available BBR dye was purchased from Himedia laboratories, India and used as received for degradation experiments.

\section{Synthesis of Poly-3-Thenoic acid/Cu-TiO nanohybrid}

In situ modified sol-gel process including chemical oxidative polymerization of 3-Thenoic acid was used to synthesize the Poly-3-Thenoic acid/Cu- $\mathrm{TiO}_{2}$ nanohybrids as reported in our previous research [17]. Briefly, $0.75 \mathrm{wt} \%$ of $\mathrm{CuCl}_{2}$ was dissolved in a minimum amount of 2-propanol in a $250 \mathrm{~mL}$ round bottom (RB) flask and stirred for $30 \mathrm{~min}$. To this $20 \mathrm{~mL}$ of n-butyl tetra ortho titanate $\left(\mathrm{Ti}(\mathrm{OBu})_{4}\right)$ was added with constant stirring. After $30 \mathrm{~min} 10 \mathrm{wt} \%$ of 3 -Thenoic acid monomer dissolved in a minimum amount of 2-propanol added to the RB flask. To cause hydrolysis and polymerization reactions $50 \mathrm{~mL}$ of milli-Q-water and $30 \mathrm{~mL}$ of aqueous ammonium persulfate solution were added which ultimately results in the formation of white precipitate that was stirred for $20 \mathrm{~h}$ at $20{ }^{\circ} \mathrm{C}$ to obtain brown colored $\mathrm{PCuT}$ nanohybrid. Finally, it was washed several times with distilled water and methanol to remove any contaminants present. In the same manner, $\mathrm{Cu}$-doped $\mathrm{TiO}_{2}$ was synthesized without adding 3-Thenoic acid and ammonium persulfate.

\section{Characterization techniques}

The crystalline nature of the samples was investigated with X-ray diffraction spectra obtained from PANanalyticaldifractometer using $\mathrm{CuK} \alpha$ radiation $(\lambda=0.15405 \mathrm{~nm})$. Fourier transform infrared spectra (FT-IR) were recorded on a Nicolet Avtar 360 in transmission mode. UV-vis diffuse reflectance spectra obtained from Shimadzu UV-2600 taking $\mathrm{BaSO}_{4}$ as a reference. The Thermogram of PCuT was recorded with Shimadzu TGA-50 thermogravimetric analyzer at a heating rate of $10{ }^{\circ} \mathrm{C} / \mathrm{min}$ in $\mathrm{N}_{2}$ atmosphere. Surface morphology and microstructure of the nanohybrid were analyzed by Field-emission scanning electron microscopy (FESEM, JSM 6300, Japan) equipped with energy dispersive X-Ray (EDX) spectroscopy for elemental analysis and high-resolution transmission electron microscopy (HRTEM) JEM-2100 JEOL. To measure the catalyst BET surface area $\mathrm{N}_{2}$ adsorption-desorption isotherms were recorded at $77.3 \mathrm{k}$ to using Quanta Chrome Nova 2200E instrument. UV-vis spectrophotometer (Shimadzu 1601) and Elico Digital pH meter (Model IIIE, EI) were used to monitor and adjust the timely percentage degradation of $\mathrm{BBR}$ and $\mathrm{pH}$ of the reaction mixture during the degradation process, respectively. 


\section{Visible light photocatalytic activity studies}

Photocatalytic degradation experiments were carried out under visible light irradiation in a photocatalytic reactor reported elsewhere [25]. Briefly, a sufficient amount of the catalyst was taken in a $150 \mathrm{~mL}$ glass beaker containing $100 \mathrm{~mL}$ of aqueous BBR solution with desired concentration, and water was circulated around the beaker to filter the IR radiation. A $400 \mathrm{~W}$ high-pressure mercury vapour lamp $(35,000 \mathrm{~lm})$ with a UV cutoff filter (Oriel 51472) was used as a visible light irradiation source and placed $20 \mathrm{~cm}$ away from the reaction beaker. To attain the adsorption-desorption equilibrium the reaction mixture was stirred in dark for $30 \mathrm{~min}$ and then started the illumination. The $\mathrm{pH}$ of the suspension was adjusted with $0.1 \mathrm{~N} \mathrm{NaOH} / 0.1 \mathrm{~N} \mathrm{HCl}$ solutions and $5 \mathrm{~mL}$ of samples were taken for every 15 min during the degradation process and centrifuged at 1,000 rpm and analyzed using UV-vis spectrophotometer by measuring the absorbance at $459 \mathrm{~nm}$ to measure the degradation of BBR. The percentage degradation of BBR was determined using the following equation.

$\%$ degradation of $\mathrm{BBR}=\frac{C_{0}-C_{t}}{C_{0}} \times 100 \%$

Where, $C_{t}$ is the concentration of BBR solution at different time intervals and $\mathrm{C}_{\mathrm{o}}$ is the initial concentration of BBR solution.

\section{Results and discussion}

\section{Structural, morphological and optical properties analyses}

From the X-ray diffraction patterns of $\mathrm{CuT}$ and $\mathrm{PCuT}$ nanohybrid that are shown in Figure 1, it is found that both the samples showed crystalline anatase phase with $2 \theta$ peaks at $25.3^{\circ}, 38.3^{\circ}, 48.2^{\circ}$, $53.8^{\circ}, 55.2^{\circ}, 62.8^{\circ}, 69.0^{\circ}, 70.4^{\circ}, 75.0^{\circ}, 82.8^{\circ}$ correspond to anatase $\mathrm{TiO}_{2}$ lattice planes $(101),(004)$, (200), (105), (211), (204), (116), (220), (215) and (224), respectively (JCPDS 21-1272). No peaks related to rutile or brookite phase and copper oxide were found, which confirms the formation of high crystalline anatase $\mathrm{TiO}_{2}$. These results imply that there is no effect of Poly-3-Thenoic acid excreted on the crystalline structure of the $\mathrm{TiO}_{2}$. The average crystallite sizes of the samples determined using Scherrer equation are found to be 7.5 and $5.2 \mathrm{~nm}$ for Cut and PCuT respectively. This decreased crystallite size of $\mathrm{TiO}_{2}$ was caused due to retardation of grain growth and control of nucleation of $\mathrm{TiO}_{2}$ nanoparticles by $\mathrm{Cu}$ and polymer material, respectively $[17,26]$.

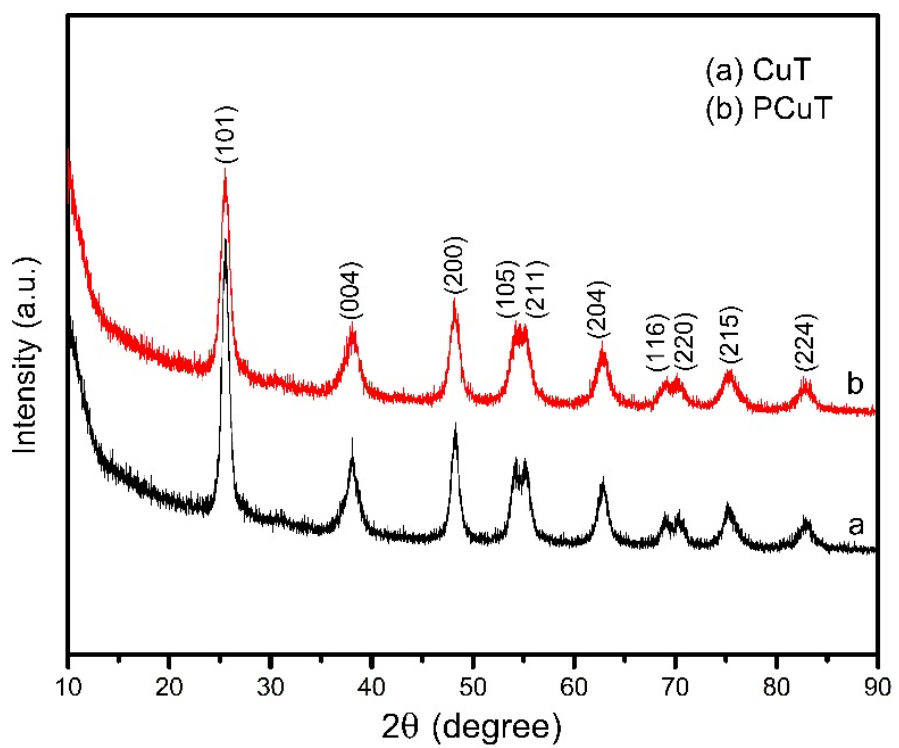

Figure 1 XRD patterns of (a) $\mathrm{Cu}$ doped $\mathrm{TiO}_{2}$ and (b) Poly-3-Thenoic acid/Cu- $\mathrm{TiO}_{2}$ nanohybrid.

FTIR spectra of CuT and PCuT nanohybrid was shown in Figure 2. In both the spectra stretching and bending vibrations of surface $-\mathrm{OH}$ and adsorbed $\mathrm{H}_{2} \mathrm{O}$ of $\mathrm{TiO}_{2}$ are found at 2,600 - 3,660 and 1,624, 2,362 $\mathrm{cm}^{-1}$ respectively [27]. From Figure 2(a) the characteristic absorbance peaks of Ti-O-Ti stretching 
vibrations are found at 435, 606 and $778 \mathrm{~cm}^{-1}$ which intensity has decreased in PCuT nanohybrid (Figure 2(b)) due to strong interaction with the polymer content. Besides these characteristic peaks of $\mathrm{TiO}_{2}, \mathrm{PCuT}$ nanohybrid also exhibited the characteristic peaks of Poly-3-Thenoic acid at 1,052, 1,135, 1,385, 1,441, 1,510 and 2,882 $\mathrm{cm}^{-1}$ correspond to $\mathrm{C}-\mathrm{S}$ stretching, $\mathrm{C}-\mathrm{H}$ bending, $\mathrm{C}=\mathrm{O}$ stretching, $\mathrm{C}=\mathrm{C}$ stretching and $\mathrm{COO}^{-}$ stretching modes which confirms the formation of nanohybrid material.

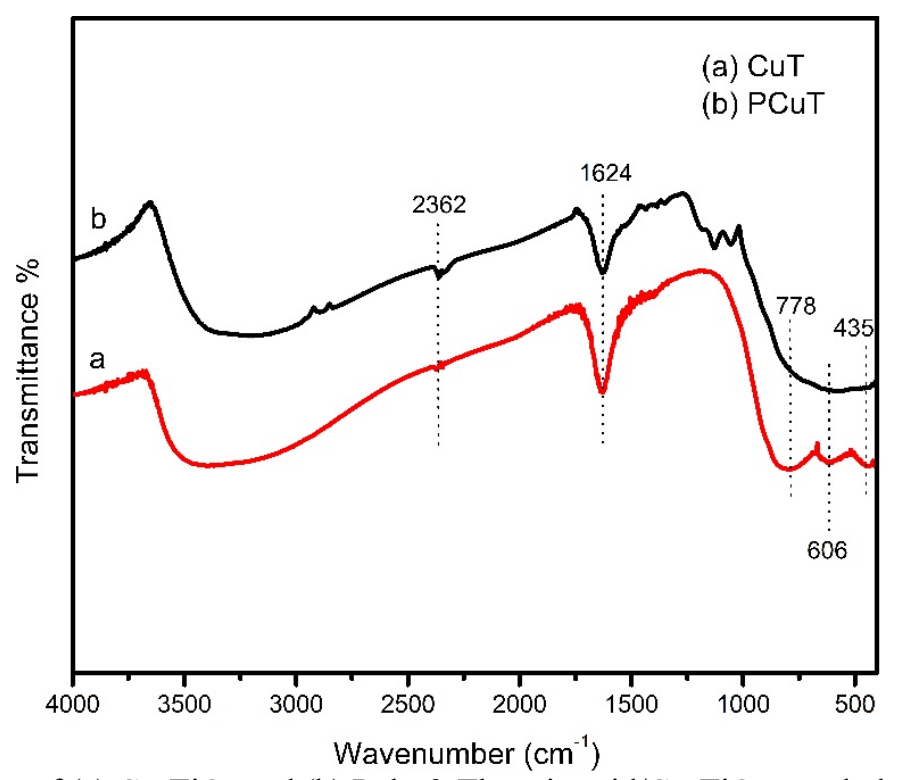

Figure 2 FTIR spectra of (a) $\mathrm{Cu}-\mathrm{TiO}_{2}$ and (b) Poly-3-Thenoic acid/Cu- $\mathrm{TiO}_{2}$ nanohybrid.

The light absorption property of the catalysts was studied by recording the UV-vis diffuse reflectance spectra shown in Figure 3. From Figure 3(a), it was observed that the light-harvesting capacity of the PCuT nanohybrid has increased much compared to $\mathrm{CuT}$, which confirms the shift in photoabsorption efficiency of the nanohybrid towards the visible portion of the electromagnetic radiation due to the sensitization of $\mathrm{TiO}_{2}$ with the high photoresponsive polymer content. The bandgap energy calculated from tauc plot method [28] shown in Figure 3(b) revealed that the bandgap of the PCuT nanohybrid has drastically decreased to $2.1 \mathrm{eV}$ compared to $2.8 \mathrm{eV}$ in $\mathrm{CuT}$ which could be attributed to the strong interaction of polymer content with the $\mathrm{Cu}-\mathrm{TiO}_{2}$.
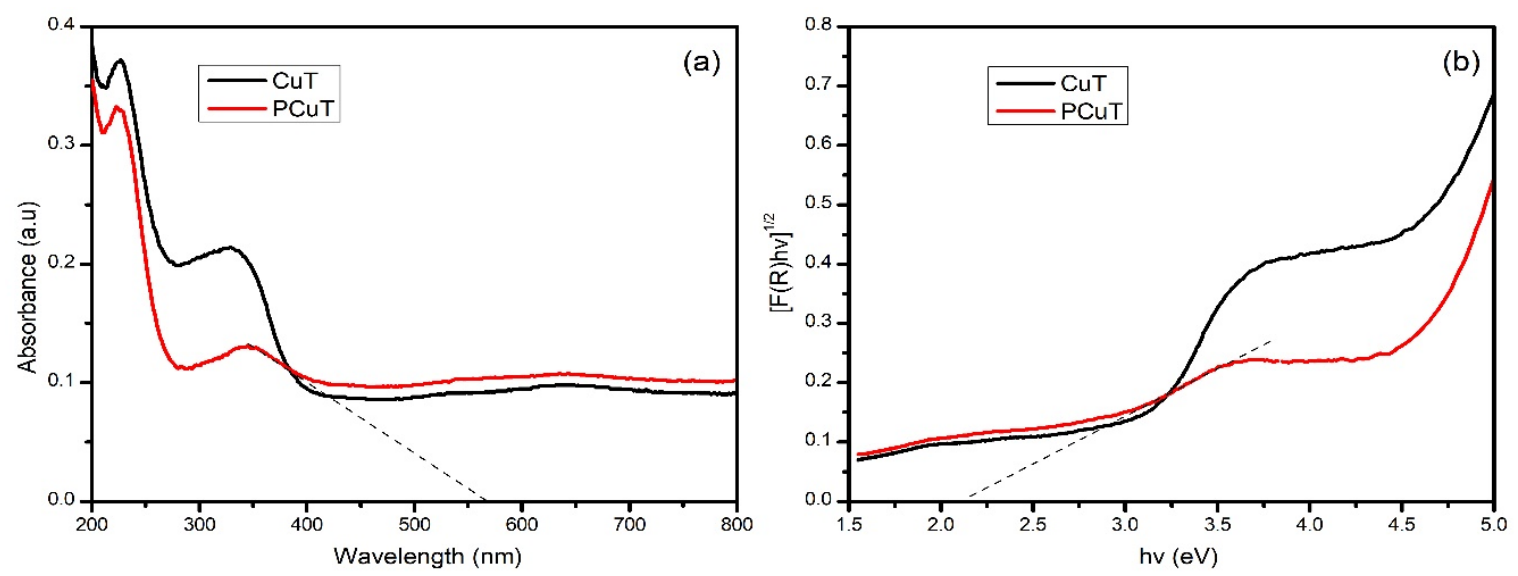

Figure 3 (a) UV-vis diffuse reflectance spectra and (b) Tauc plot for bandgap measurement of CuT and PCuT nanohybrid. 
FESEM, EDX, HRTEM, and SAED analyses were performed to determine the surface morphology, elemental composition, and microstructure of Poly-3-Thenoic acid/Cu- $\mathrm{TiO}_{2}$ nanohybrid and the images are shown in Figure 4. From Figure 4(b), PCuT showed well distributed multiparticle aggregates of hybrid nanoparticles with small size and smooth surface compared to large irregular shaped aggregated $\mathrm{Cu}-\mathrm{TiO}_{2}$ nanoparticles with a rough surface (Figure 4(a)). This can be attributed to the effective encapsulation of polymer content on $\mathrm{Cu}-\mathrm{TiO}_{2}$ nanoparticles during the synthesis process. From the EDX spectrum (inset of Figure 4(b)) all the constituent elements of both the $\mathrm{Cu}-\mathrm{TiO}_{2}$ and Poly-3-Thenoic acid were found to be present in the PCuT nanohybrid without any impurities. From Figure 4(c), small aggregates of spherical shaped $\mathrm{TiO}_{2}$ particles are observed due to the polymer interaction. The HRTEM image (Figure 4(d)) revealed the close contact between polymer and high crystalline anatase $\mathrm{TiO}_{2}$ having an interplanar spacing of $0.352 \mathrm{~nm}$ which corresponds to the d-spacing of anatase lattice plane (101). The SAED pattern indexed by concentric rings (insect of Figure 4(d)) also further confirmed the presence of anatase (101) $\mathrm{TiO}_{2}$. The average crystallite size of the PCuT nanohybrid was determined using Image $\mathrm{J}$ software and found to be $4.8 \mathrm{~nm}$ which is in good agreement with the crystallite size measured from XRD results.
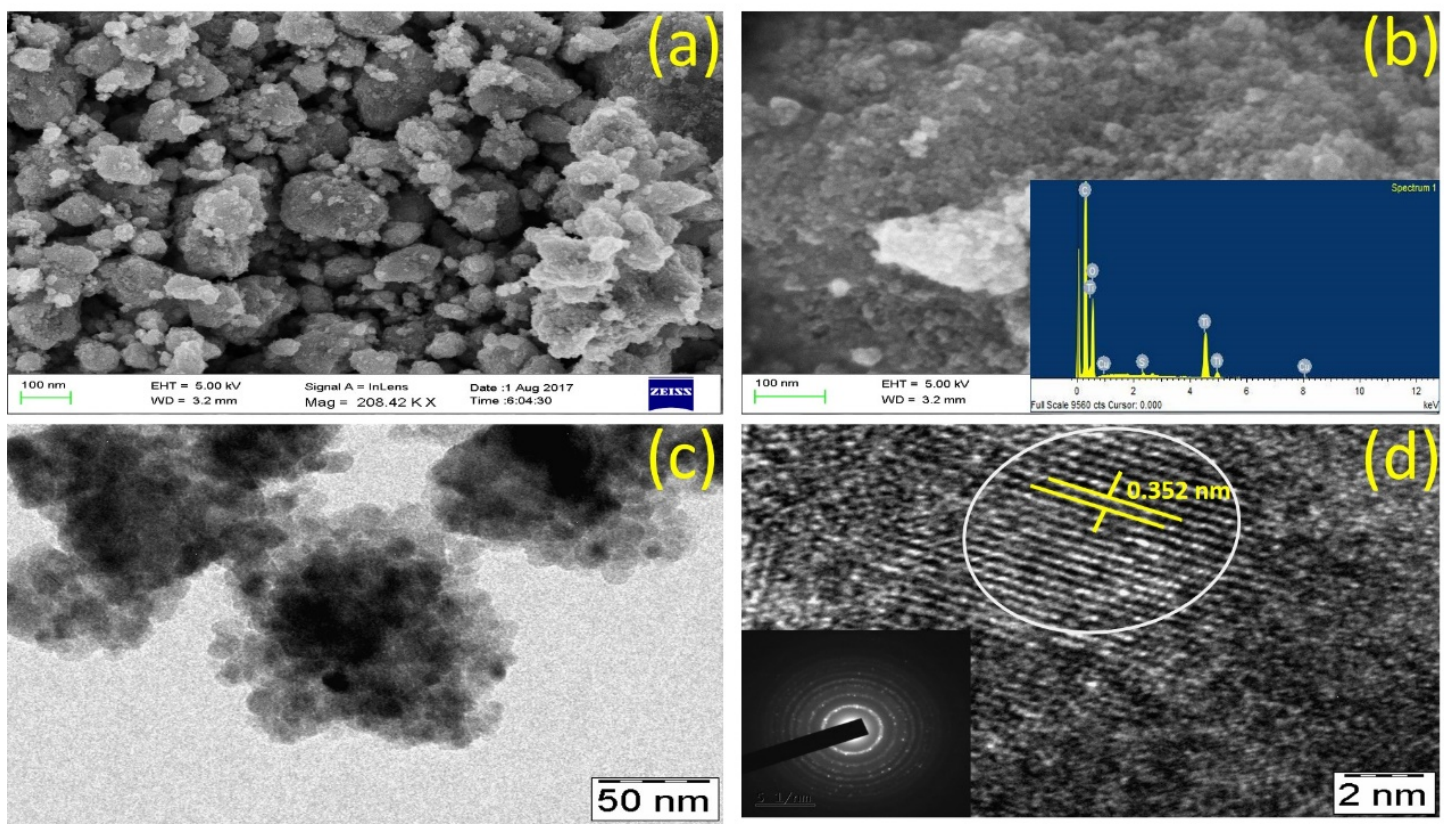

Figure 4 FESEM images of (a) $\mathrm{Cu}-\mathrm{TiO}_{2}$ and (b) Poly-3-Thenoic acid/Cu- $\mathrm{TiO}_{2}$ nanohybrid with EDX spectrum (insect of (4b)); (c) TEM and (d) HRTEM images of Poly-3-Thenoic acid/Cu-TiO 2 nanohybrid with SAED pattern (insect of $(4 \mathrm{~d}))$.

Nitrogen adsorption-desorption isotherms were recorded for $\mathrm{CuT}$ and $\mathrm{PCuT}$ to study their surface area and porosity nature and shown in Figure 5. The results revealed that both the samples are having mesoporous nature, which was confirmed by the observed type IV pattern with the H3 hysteresis loop [29]. In comparison with the CuT curve (Figure 5(a)), the increased number of mesopores and their pore size/volume in the PCuT nanohybrid (Figure 5(b)) was confirmed by the extended hysteresis loop at the high-pressure region and increased amount of $\mathrm{N}_{2}$ adsorption. Moreover, the determined BET specific surface area, $183.1685 \mathrm{~m}^{2} / \mathrm{g}$ of PCuT nanohybrid strongly supported the above results which can be well correlated with the small particle of the $\mathrm{TiO}_{2}$ nanoparticles determined by the TEM results. 


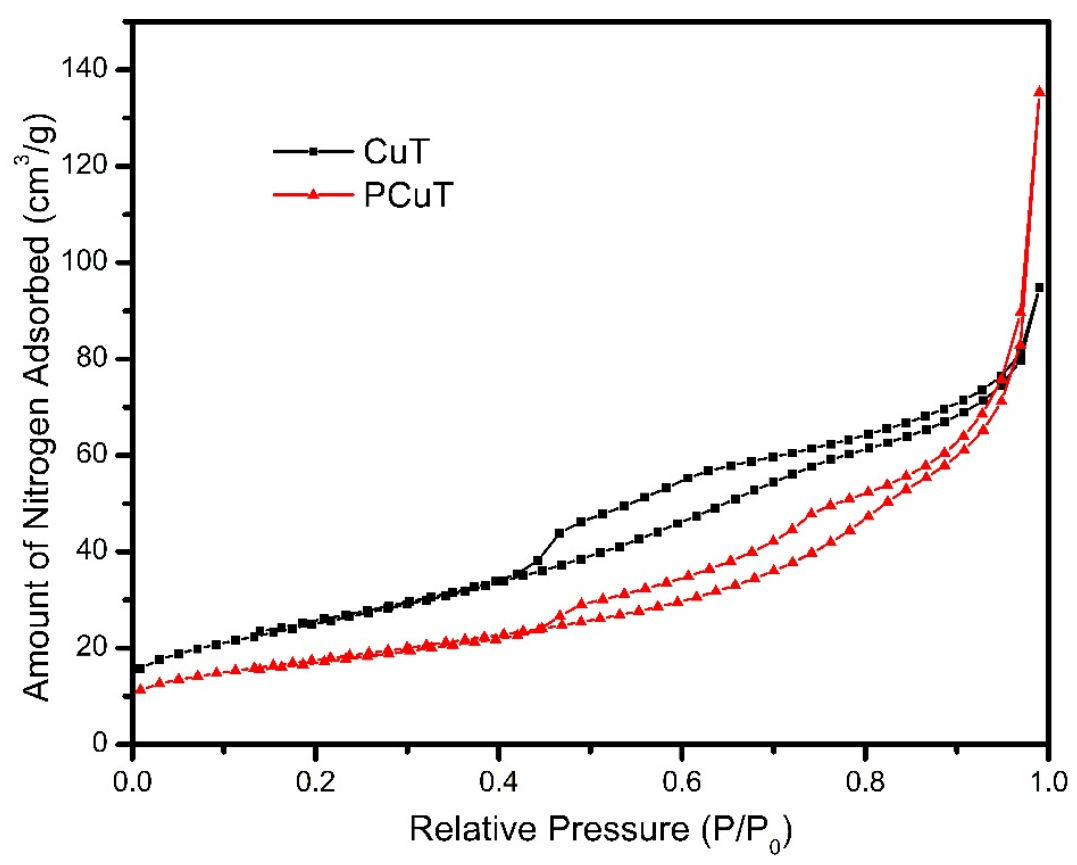

Figure 5 Nitrogen adsorption-desorption isotherms of $\mathrm{CuT}$ and $\mathrm{PCuT}$ nanohybrid.

\section{Photocatalytic degradation activity studies}

The photocatalytic degradation efficiency of the synthesized catalysts was studied by degrading the diazo dye pollutant BBR under visible light irradiation after $30 \mathrm{~min}$ of dark reaction. To attain the best photocatalytic efficiency, the effects of various photocatalyst/dye reaction parameters were investigated, optimized, and presented in Figures 6(a) - 6(d). In the beginning, a blank control experiment was performed in the absence of photocatalyst to study the photostability of the BBR, which shown $<1 \%$ degradation in $120 \mathrm{~min}$.

The effect of Poly-3-Thenoic acid on the photocatalytic performance of PCuT nanohybrid shown in Figure 6(a), which revealed the enormous increase in the catalytic performance compared to $\mathrm{CuT}$ and degraded the BBR in $120 \mathrm{~min}$. This can be strongly attributed to the effective sensitization of $\mathrm{TiO}_{2}$ nanoparticles by the polymer content.

As the degradation of the ionic dye pollutants presented in wastewater depends on the $\mathrm{pH}$ of the reaction solution, the effect of the $\mathrm{pH}$ on the photocatalytic degradation efficiency of the $\mathrm{PCuT}$ nanohybrid was studied by varying the $\mathrm{pH}$ from 2 to 6 as the BBR is an anionic dye which attracts more towards the positively charged catalyst surface attained in this $\mathrm{pH}$ range. From the results shown in Figure 6(b) the degradation percentage was high at $\mathrm{pH} 4$ due to increased electrostatic interaction between positively charged $\mathrm{TiO}_{2}$ surface and negatively charged BBR dye molecule and less at $\mathrm{pH} 2$ and 6 , which indicated that at $\mathrm{pH}$ below 4 , the $\mathrm{H}^{+}$ions capture the photogenerated electrons and at $\mathrm{pH}$ above 4 the extent of positive surface charge of the catalyst decreases which ultimately diminishes the photocatalytic activity.

To minimize the wastage of the catalyst and to achieve better catalytic performance, the effect of catalyst dosage was studied by varying its dosage from 0.1 to $0.2 \mathrm{~g}$ and the results are shown in Figure 6(c). Here, it was found that the degradation percentage of BBR has increased from 0.1 to $0.15 \mathrm{~g}$ of catalyst loading, which is due to the increased surface area of the catalyst for adsorption of a greater number of dye molecules. But a further increase in the catalyst loading had caused the turbidity of the reaction mixture that scatters the incident irradiation which decreased the photocatalytic activity. And also, there is a possibility of collisions between activated and ground state catalyst molecules that causes the deactivation of the overall catalyst activity.

The effect of the initial BBR dye concentration on the photocatalytic activity of PCuT nanohybrid was investigated by varying its concentration from 5 to $20 \mathrm{mg} / \mathrm{L}$ and the results shown in Figure 6(d). Upon increasing the dye concentration from $5 \mathrm{mg} / \mathrm{L}$ to $10 \mathrm{mg} / \mathrm{L}$ the percentage degradation was increased and almost complete dye degraded in $75 \mathrm{~min}$ of irradiation. Above this concentration level, the degradation percentage started to decrease due to the blanket effect i.e "once a layer of dye molecules is 
adsorbed on the catalyst surface, another layer adsorbed on it may not be possible. Hence, there is a delay in the adsorption of the $2^{\text {nd }}$ layer, until the $1^{\text {st }}$ layer gets completely degraded" [5].

A comparison of photocatalytic degradation efficiency of PCuT with various previously reported polymer/ $\mathrm{TiO}_{2}$ nanohybrids on different organic pollutants is given in Table 1 to establish its ehanced photocatalytic activity over the other reported catalysts in literature.

Table 1 Comparison of photocatalytic degradation efficiency of various polymer/ $/ \mathrm{TiO}_{2}$ nanohybrids on different organic pollutants.

\begin{tabular}{|c|c|c|c|c|}
\hline Nanohybrid photocatalyst & Organic pollutant & $\begin{array}{c}\% \% \text { of } \\
\text { degradation }\end{array}$ & $\begin{array}{c}\text { Degradation } \\
\text { time }\end{array}$ & Reference \\
\hline Poly-(fluorine-co-thiophene)/ $/ \mathrm{TiO}_{2}$ & Phenol & $74 \%$ & $600 \mathrm{~min}$ & 30 \\
\hline Poly(3-hexylthiophene)/ $/ \mathrm{TiO}_{2}$ & Methyl orange & $88 \%$ & $600 \mathrm{~min}$ & 31 \\
\hline Polypyrrole/ $\mathrm{TiO}_{2}$ & Methyl Orange & $90 \%$ & $160 \mathrm{~min}$ & 32 \\
\hline Polyaniline/ $\mathrm{TiO}_{2}$ & Methylene Blue & $81 \%$ & $120 \mathrm{~min}$ & 33 \\
\hline Polythiophene $/ \mathrm{Cu}-\mathrm{TiO}_{2}$ & Orange $\mathrm{G}$ & $98 \%$ & $90 \mathrm{~min}$ & 16 \\
\hline Poly-3-Thenoic acid/Cu- $\mathrm{TiO}_{2}$ & Bismark Brown R & $99.9 \%$ & $75 \mathrm{~min}$ & Present study \\
\hline
\end{tabular}
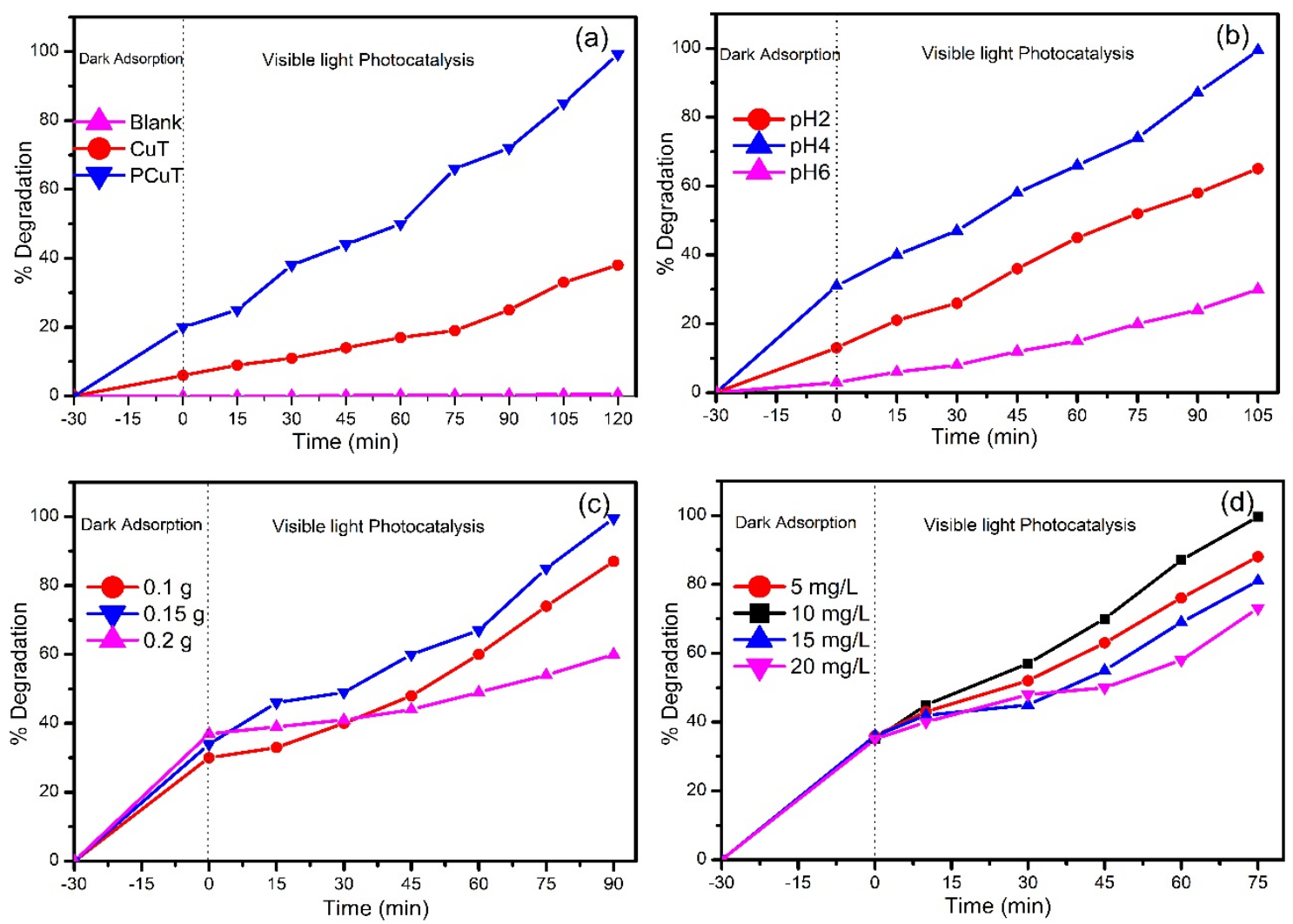

Figure 6 (a) Effect of polymer content on the \% degradation of BBR by PCuT nanohybrid compared with $\mathrm{Cu}-\mathrm{TiO}_{2}$ studied at catalyst dosage of $0.1 \mathrm{~g}$ and $[\mathrm{BBR}]=10 \mathrm{mg} / \mathrm{L}$; (b) Effect of $\mathrm{pH}$ on $\%$ degradation of BBR by PCuT nanohybrid studied at catalyst dosage of $0.1 \mathrm{~g}$ and [BBR] $=10 \mathrm{mg} / \mathrm{L}$; (c) Effect of catalyst loading on \% degradation of BBR by PCuT nanohybrid at solution $\mathrm{pH} 4$ and $[\mathrm{BBR}]=10 \mathrm{mg} / \mathrm{L}$; (d) Effect of initial BBR concentration on its \% of degradation by $\mathrm{PCuT}$ nanohybrid at solution $\mathrm{pH} 4$, catalyst loading $0.15 \mathrm{~g}$ and $[\mathrm{BBR}]=10 \mathrm{mg} / \mathrm{L}$. 


\section{Conclusions}

Poly-3-Thenoic acid/Cu- $\mathrm{TiO}_{2}$ nanohybrid material was successfully synthesized by in situ modified sol-gel process including chemical oxidative polymerization. Due to the effective encapsulation and sensitization of the polymer, the grain growth and nucleation of $\mathrm{Cu}-\mathrm{TiO}_{2}$ nanoparticles were greatly restricted and resulted in decreased particle size $(5.2 \mathrm{~nm})$, increased surface area $\left(183.1685 \mathrm{~m}^{2} / \mathrm{g}\right)$ and narrowed bandgap energy $(2.1 \mathrm{eV})$. These results were well correlated with the shifting of photon absorption capacity of $\mathrm{TiO}_{2}$ nanoparticles from UV to visible range and enhanced photocatalytic degradation of BBR dye under visible light irradiation. Finally, the optimization of various catalyst/dye reaction parameters i.e polymer content $10 \mathrm{wt} \%, \mathrm{pH} 4$, catalyst dosage $0.15 \mathrm{~g}$, and initial BBR concentration $10 \mathrm{mg} / \mathrm{L}$ lead to almost complete degradation of BBR in $75 \mathrm{~min}$ of visible light irradiation. Hence, the present study reports promising nanohybrid material for the degradation of various dye pollutants from industrial wastewater to minimize water pollution for a better environment.

\section{Acknowledgments}

We thank the Science and Engineering Research Board, Department of Science and Technology, Government of India for providing financial assistance to carry out this research [Project file number SB/EMEQ/400/2014].

\section{References}

[1] A Jraba, Z Anna and E Elaloui. Effects of $\mathrm{Sr}^{2+}, \mathrm{Fe}^{3+}$ and $\mathrm{Al}^{3+}$ doping on the properties of $\mathrm{TiO}_{2}$ prepared using the sol-gel method. C.R. Chim. 2019; 22, 648-58.

[2] W Zhang, N Luo, S Huang, NL Wu and M Wei. Sulfur-Doped Anatase $\mathrm{TiO}_{2}$ as an Anode for HighPerformance Sodium-Ion Batteries. ACS Appl. Energy Mater. 2019; 2, 3791-7.

[3] TH Kim, GM Go, HB Cho, Y Song, CG Lee and YH Choa. A novel synthetic method for N doped $\mathrm{TiO}_{2}$ nanoparticles through plasma-assisted electrolysis and photocatalytic activity in the visible region. Front. Chem. 2019; 6, 458.

[4] KVD Lakshmi, TS Rao, JS Padmaja, IM Raju, SA Alim, and P Kalyani. Visible light driven mesoporous $\mathrm{Mn}$ and $\mathrm{S}$ co-doped $\mathrm{TiO}_{2}$ nano material: Characterization and applications in photocatalytic degradation of indigo carmine dye and antibacterial activity. Environ. Nanotechnol. Monit. Manage. 2018; 10, 494-504.

[5] KVD Lakshmi, TS Rao, JS Padmaja, IM Raju and MR Kumar. Structure, photocatalytic and antibacterial activity study of Mesoporous $\mathrm{Ni}$ and $\mathrm{S}$ co-doped $\mathrm{TiO}_{2}$ nano material under visible light irradiation. Chin. J. Chem. Eng. 2019; 27, 1630-41.

[6] SA Alim, TS Rao, IM Raju, MR Kumar and KVD Lakshmi. Fabrication of visible light driven nano structured Copper, Boron codoped $\mathrm{TiO}_{2}$ for photocatalytic removal of Lissamine Green B. J. Saudi Chem. Soc. 2019; 23, 92-103.

[7] RK Mulpuri, SR Tirukkovalluri, MR Imandi, SA Alim and VDL Kapuganti. Zinc and boron codoped nanotitania with enhanced photocatalytic degradation of acid red 6A under visible light irradiation. Sustainable Environ. Res. 2019; 29, 29.

[8] G Sanzone, M Zimbone, G Cacciato, F Ruffino, R Carles, V Privitera and MG Grimaldi. Ag/TiO nanocomposite for visible light-driven photocatalysis. Superlattices Microstruct. 2018; 123, 394402.

[9] M Dahl, Y Liu and Y Yin. Composite Titanium Dioxide Nanomaterials. Chem. Rev. 2014; 114, 9853-89.

[10] JS Padmaja, TS Rao, KVD Lakshmi, IM Raju. Fabrication of hetero-structured mesoporours $\mathrm{TiO}_{2}$ $\mathrm{SrTiO}_{3}$ nanocomposite in presence of Gemini surfactant: Characterization and application in catalytic degradation of Acid Orange. J. Environ. Chem. Eng. 2018; 6, 6457-67.

[11] BS Mohan, K Ravi, RB Anjaneyulu, GS Sree and K Basavaiah. $\mathrm{Fe}_{2} \mathrm{O}_{3} / \mathrm{RGO}$ nanocomposite photocatalyst: Effective degradation of 4-Nitrophenol. Phys. B: Condens. Matter. 2019; 553, 190-4.

[12] MA Ramazanov, FV Hajiyeva and AM Maharramov. Structure and properties of $\mathrm{PP} / \mathrm{TiO}_{2}$ based polymer nanocomposites. Integr. Ferroelectr. 2018; 192, 103-12.

[13] H Feng, $\mathrm{H} \mathrm{Xu}, \mathrm{H}$ Feng, Y Gao and X Jin. The sol-gel synthesis and photocatalytic activity of Gd$\mathrm{SiO}_{2}-\mathrm{TiO}_{2}$ photocatalyst. Chem. Phys. Lett. 2019; 733, 136676.

[14] BS Mohan, K Basavaiah. Fabrication of multifunctional TANI/ $\mathrm{Cu}_{2} \mathrm{O} / \mathrm{Ag}$ nanocomposite for environmental abatement. Sci. Rep. 2020; 10, 14080.

[15] N Turkten, Z Cinar, A Tomruk and $\mathrm{M}$ Bekbolet. Copper-doped $\mathrm{TiO}_{2}$ photocatalysts: Applications to drinking water by humic matter degradation. Environ. Sci. Pollut. Res. 2019; 26, 36096-106. 
[16] MR Chandra, TS Rao, HS Kim, SVN Pammi, N Prabhakarrao and IM Raju. Hybrid copper doped titania/polythiophene nanorods as efficient visible light-driven photocatalyst for degradation of organic pollutants. J. Asian Ceram. Soc. 2019; 5, 436-43.

[17] IM Raju, TS Rao, KVD Lakshmi, MR Chandra, JS Padmaja and G Divya. Poly-3-Thenoic acid sensitized, copper doped anatase/brookite $\mathrm{TiO}_{2}$ nanohybrids for enhanced photocatalytic degradation of an organophosphorus pesticide. J. Environ. Chem. Eng. 2019; 7, 103211.

[18] N Paradee and A Sirivat. Synthesis of poly(3,4-ethylenedioxythiophene) nanoparticles via chemical oxidation polymerization. Polym. Int. 2014; 63, 106-13.

[19] Y Zhu and Y Dan. Photocatalytic activity of poly(3-hexylthiophene)/titanium dioxide composites for degrading methyl orange. Sol. Enegy. Mater. Sol. Cells. 2010; 94, 1658-64.

[20] B Fatima, SI Siddiqui, R Ahmed and SA_Chaudhry. Green synthesis of $\mathrm{f}_{-} \mathrm{CdWO}_{4}$ for photocatalytic degradation and adsorptive removal of Bismarck Brown R dye from water. Water Resour. Ind. 2019; 22, 100119.

[21] MW Girolami and RW Rousseau. Effects of Bismarck Brown R on the growth rates of large and small potassium alum crystals. J. Cryst. Growth. 1985; 71, 220-4.

[22] JM Vazquez, E Martinez, J Roca, P Coy and S Ruiz. Use of triple stain technique for simultaneous assessment of vitality and acrosomal status in boar spermatozoa. Theriogenology. 1992; 38, 843-52.

[23] J Mittal, V Thakur and A Mittal. Batch removal of hazardous azo dye Bismark Brown R using waste material hen feather. Ecolog. Eng. 2013; 60, 249-53.

[24] GM Sole and JK Chipman. The mutagenic potency of Chrysoidines and Bismark Brown dyes. Carcinogenesis. 1986; 7, 1921-3.

[25] BS Mohan, GP Naidu, M Ravichandra, SJ Rani, RB Anjaneyulu and CV Ramana. Flower like $\mathrm{SnO}_{2}-$ $\mathrm{Fe}_{2} \mathrm{O}_{3}$-rGO ternary composite as highly efficient visible light induced photocatalyst for the degradation of organic pollutants from contaminated water. J. Mater. Res. Technol. 2020; 9, 12461-72.

[26] $\mathrm{M}$ Khairy and $\mathrm{W}$ Zakaria. Effect of metal-doping of $\mathrm{TiO}_{2}$ nanoparticles on their photocatalytic activities toward removal of organic dyes. Egypt. J. Pet. 2014; 23, 419-26.

[27] H Diker, C Varlikli, K Mizrak and A Dana. Characterizations and photocatalytic activity comparisons of $\mathrm{N}$-doped nc- $\mathrm{TiO}_{2}$ depending on synthetic conditions and structural differences of amine sources. Energy. 2011; 36, 1243-54.

[28] N Ghobadi. Band gap determination using absorption spectrum fitting procedure. Int. Nano Lett. $2013 ; 3,2$.

[29] Y Nishi and M Inagaki. Gas adsorption/desorption isotherm for pore structure characterization. In: $\mathrm{M}$ Inagaki and F Kang (Eds). $1^{\text {st }}$ ed. Materials science and engineering of carbon: Characterization. Elsevier Inc., UK, 2016, p. 227-47.

[30] S Lin, Q Rongliang, M Yueqi, Z Dongdong, W Hui and X Ya. Photodegradation of phenol in a polymer-modified $\mathrm{TiO}_{2}$ semiconductor particulate system under the irradiation of visible light. Catal. Commun. 2007; 8, 429-33.

[31] W Desong, Z Jie, L Qingzhi, L Xueyan, D Yandong and A Jing. Characterization and photocatalytic activity of poly(3-hexylthiophene)-modified $\mathrm{TiO}_{2}$ for degradation of methyl orange under visible light. J. Hazard. Mater. 2009; 169, 546-50.

[32] W Desong, W Yanhong, L Xueyan, L Qingzhi, A Jing and Y Jianxia. Sunlight photocatalytic activity of polypyrrole- $\mathrm{TiO}_{2}$ nanocomposites prepared by 'in situ' method. Catal. Commun. 2008; 9 , 1162-6.

[33] W Fang, M Shixiong, H Yuqi and F Lei. Visible-light-induced photocatalytic degradation of methylene blue with polyaniline-sensitized $\mathrm{TiO}_{2}$ composite photocatalysts. Superlattices Microstruct. 2010; 48, 170-80. 